\title{
Hypertension and left ventricular hypertrophy
}

\author{
Wilbert S. Aronow \\ Cardiology Division, Department of Medicine, Westchester Medical Center and New York Medical College Valhalla, NY, USA \\ Correspondence to: Wilbert S. Aronow, MD, FACC, FAHA. Professor of Medicine, Cardiology Division, Westchester Medical Center and New York \\ Medical College, Macy Pavilion, Room 141, Valhalla, NY 10595, USA. Email: wsaronow@aol.com.
}

Submitted Apr 10, 2017. Accepted for publication May 01, 2017.

doi: 10.21037/atm.2017.06.14

View this article at: http://dx.doi.org/10.21037/atm.2017.06.14

Left ventricular hypertrophy ( $\mathrm{LVH})$ is an abnormal increase in left ventricular mass. which is a marker for and contributes to coronary events, stroke, heart failure, peripheral arterial disease, and cardiovascular mortality in patients with hypertension (1-12). LVH is commonly measured by electrocardiography, echocardiography, and magnetic resonance imaging Concentric LVH is an increased left ventricular mass index with a relative wall thickness $\geq 0.45$ (1). Eccentric LVH is an increased left ventricular mass index with a relative wall thickness $<0.45$ (1). Concentric left ventricular remodeling is a relative wall thickness $\geq 0.45$ with a normal left ventricular mass index. Factors influencing left ventricular geometry in persons with hypertension include: (I) the severity, duration, and rapidity of onset of the increased pressure load; (II) the volume load; (III) age, race/ethnicity, and sex; (IV) comorbidities such as coronary artery disease, diabetes mellitus, obesity, and valvular heart disease; (V) the neurohormonal milieu; (VI) alterations of the extracellular matrix; and (VII) genetic factors (13). Blacks with hypertension are more likely than whites with hypertension to develop concentric LVH (13). Women with hypertension are more likely than men with hypertension to develop concentric LVH (13). Increasing age in patients with hypertension is associated with concentric LVH (13). Diabetes mellitus in patients with hypertension is associated with concentric LVH, whereas obesity, which is a volume overload state, and coronary artery disease in patients with hypertension are more likely to be associated with eccentric LVH (13).

The electrocardiogram is less sensitive than the echocardiogram or magnetic resonance imaging in diagnosing LVH. In a blinded prospective study of 476 patients aged 62 years and older, echocardiographic LVH was $67 \%$ to $71 \%$ present in 167 patients (35\%) (14). The sensitivity of 5 different electrocardiographic criteria in diagnosing $\mathrm{LVH}$ varied from $12 \%$ to $29 \%$, the specificity from $93 \%$ to $96 \%$, the positive predictive value from $62 \%$ to $71 \%$, and the negative predictive value from $67 \%$ to $71 \%$ (14). The Cornell criteria (15) had the highest sensitivity (29\%) in predicting $\mathrm{LVH}$, a specificity of $93 \%$, a positive predictive value of $69 \%$, and a negative predictive value of $71 \%$ (14).

In a prospective study of 84 blacks and 326 whites older than 62 years with hypertension, echocardiographic LVH was present in $71 \%$ of blacks and in $56 \%$ of whites (1). Electrocardiographic LVH was present in $20 \%$ of blacks and in $15 \%$ of whites (1). Concentric LVH was present in $60 \%$ of blacks and in $40 \%$ of whites (1). Eccentric LVH was present in $12 \%$ of blacks and in $17 \%$ of whites (1). At 37-month follow-up of blacks, echocardiographic LVH increased the incidence of new coronary events 3.33 times, new stroke 2.76 times, and new congestive heart failure 3.69 times (1). At 43-month follow-up of whites, echocardiographic LVH increased the incidence of new coronary events 2.72 times, new stroke 2.76 times, and new congestive heart failure 3.69 times (1). At 37-month follow-up of blacks, electrocardiographic $\mathrm{LVH}$ increased the incidence of new coronary events 1.49 times, new stroke 1.79 times, and new congestive heart failure 1.31 times (1). At 43 -month follow-up of whites, electrocardiographic LVH increased the incidence of new coronary events 1.41 times, new stroke 1.94 times, and new congestive heart failure 1.58 times (1). In elderly blacks, compared with eccentric LVH, concentric LVH increased the incidence of new coronary events 1.48 times, new stroke 1.2 times, and new congestive heart failure 1.73 times (1). In elderly whites, compared with 
eccentric LVH, concentric LVH increased the incidence of new coronary events 1.42 times, new congestive heart failure 1.82 times, and had a similar incidence of new stroke (1). Echocardiographic LVH (odds ratio 3.21) and concentric LVH (odds ratio $=2.63$ ) were significant independent variables for new coronary events in the final multiple logistic regression model for all patients with hypertension (1). Echocardiographic LVH (odds ratio 4.17) and electrocardiographic LVH (odds ratio $=2.10$ ) were significant independent variables for new stroke in the final multiple logistic regression model for all patients with hypertension (1). Echocardiographic LVH (odds ratio 2.57) and concentric LVH (odds ratio $=2.44$ ) were significant independent variables for new coronary events in the final multiple logistic regression model for all patients with hypertension (1).

At 4-year follow-up of 406 men, mean age 68 years, and 735 women, mean age 69 years, in the Framingham Heart Study, echocardiographic LVH increased the risk of new coronary events 1.67 times for men and 1.60 times for women per 50 grams/meter increase in left ventricular mass/ height (3). Echocardiographic LVH was 15.3 times more sensitive in predicting new coronary events in older men and 4.3 times more sensitive in predicting new coronary events in older women than was electrocardiographic LVH (3).

At 10.2-year follow-up of 253 patients with hypertension, echocardiographic LVH increased the incidence of cardiovascular events 2.17 times, cardiovascular death 28 times, and all-cause mortality 8 times (4). Patients with concentric LVH had the highest incidence of cardiovascular events and of mortality. Electrocardiographic LVH did not predict risk (4). At 37-month follow-up of 360 elderly patients with hypertension or coronary artery disease, echocardiographic LVH increased the incidence of new coronary events 2.0 times and of new stroke 2.8 times (6). Electrocardiographic LVH increased the incidence of new coronary events 1.4 times and of new stroke 1.7 times (6). Echocardiographic LVH was 4.3 times more sensitive in predicting new coronary events and 4.0 times more sensitive in predicting new stroke than was electrocardiographic LVH (6).

At 4-year follow-up of 3,220 persons aged 40 years and older in the Framingham Heart Study, echocardiographic $\mathrm{LVH}$ increased the risk of cardiovascular events 1.49 times for men and 1.57 times for women per 50 grams/meter increase in left ventricular mass/height, the risk of cardiovascular death 1.73 times for men and
2.12 times for women per 50 grams/meter increase in left ventricular mass/height, and the risk of all-cause mortality 1.49 times for men and 2.01 times for women per 50 grams/ meter increase in left ventricular mass/height (7). At 6- to 7 -year follow-up of 5,888 persons, mean age 73 years, in the Cardiovascular Health Study, compared to the lowest quartile of echocardiographic left ventricular mass, the highest quartile of echocardiographic left ventricular mass increased the incidence of coronary events 1.43 times, the incidence of stroke 1.52 times, and the incidence of congestive heart failure 3.36 times (8). Compared with normal left ventricular geometry, eccentric LVH increased the incidence of coronary events 2.05 times and for congestive heart failure 2.95 times. Compared with normal left ventricular geometry, concentric LVH increased the incidence of coronary events 1.61 times and for congestive heart failure 3.32 times (8).

At 42-month follow-up of 2,638 persons, mean age 81 years, the incidence of new congestive heart failure was increased 2.73 times in persons with persistent electrocardiographic LVH compared with persons without electrocardiographic LVH (9). At 4.8-year follow-up of 922 patients with hypertension, patients with both echocardiographic $\mathrm{LVH}$ and electrocardiographic LVH had a 5.3 times higher incidence of hospitalization for congestive heart failure than patients without electrocardiographic or echocardiographic LVH (10). Patients with both echocardiographic LVH and electrocardiographic LVH had a 2.6 times higher incidence of hospitalization for congestive heart failure than patients without electrocardiographic LVH who had echocardiographic LVH (10).

At 10-year follow-up of 2,577 community-dwelling adults, mean age 72 years, in the Cardiovascular Health study, addition of a 1-standard deviation higher echocardiographic left ventricular mass index to the 10-year risk prediction models containing traditional risk factors improved risk prediction for incident coronary heart disease $25 \%$, for incident coronary heart disease or heart failure or stroke $24 \%$, and for incident congestive heart failure $51 \%$ (11). The Multi-Ethnic Study of Atherosclerosis (MESA) Study performed cardiac magnetic resonance imaging for measurement of left ventricular mass and geometry to predict incident cardiovascular events in 5,098 persons aged 45 to 84 years old (12). At 4-year follow-up, concentric LVH increased the incidence of coronary heart disease 2.1 times per gram $/ \mathrm{mL}$ of left ventricular mass to volume ratio and the incidence of stroke 4.2 times per $\mathrm{gram} / \mathrm{mL}$ of left ventricular mass to volume ratio (12). Left 
ventricular mass alone increased the incidence of congestive heart failure 1.4 times per $10 \%$ increase in left ventricular mass (12). There are no data comparing the prognostic value of left ventricular mass and geometry obtained by magnetic resonance imaging versus by echocardiography.

At 2.71-year follow-up of 694 persons, mean age 50 years, with hypertension, echocardiographic concentric left ventricular remodeling increased cardiovascular events 2.56 times compared with echocardiographic normal left ventricular geometry (16). Echocardiograms were obtained in 9,771 patients older than 70 years with a normal left ventricular ejection fraction who were followed for 3.1 years (17). All-cause mortality was $15.9 \%$ in patients with concentric LVH, $15.5 \%$ in patients with concentric left ventricular remodeling, $13.7 \%$ in patients with eccentric $\mathrm{LVH}$, and $11.5 \%$ in patients with normal left ventricular geometry (17).

A prospective cohort sub-study of 941 patients aged 55 to 80 years old in the Losartan Intervention for Endpoint Reduction in Hypertension (LIFE) trial with hypertension and electrocardiographic LVH had left ventricular mass measured by echocardiography (18). At 4.8-year followup, reduction in echocardiographic left ventricular mass index by antihypertensive drug treatment reduced the incidence of cardiovascular mortality by $38 \%$, stroke by $24 \%$, myocardial infarction by $15 \%$, and all-cause mortality by $28 \%$, independent of systolic blood pressure and assigned treatment (18). At 4-year follow-up of 9,193 persons aged 55 to 80 years old with hypertension and electrocardiographic LVH diagnosed by Cornell criteria or by Sokolow-Lyon voltage criteria in the LIFE trial, less severe electrocardiographic LVH by the Cornell criteria and by the Sokolow-Lyon voltage criteria were associated with a $14 \%$ and $17 \%$, respectively, decrease in the composite endpoint of cardiovascular death, myocardial infarction, or stroke (19). At 4.7-year follow-up of 8,479 persons, mean age 67 years old, with hypertension and electrocardiographic LVH diagnosed by the Cornell criteria, less severe electrocardiographic $\mathrm{LVH}$ was associated with a $19 \%$ reduction in heart failure hospitalization for every $817-\mathrm{mm} \cdot \mathrm{msec}$ lower Cornell product (20). In an outpatient clinic, at 67-month follow-up of patients with hypertension and echocardiographic LVH, regression of LVH occurred in $23 \%$ of patients treated with antihypertensive drugs (21).

A meta-analysis was performed of 5 studies including 3,149 patients, mean age range 48 to 66 years old, with hypertension investigating the effect of regression of echocardiographic LVH on cardiovascular events (22). Follow-up ranged from 3 to 9 years. Regression of echocardiographic LVH was associated with a $46 \%$ reduction in cardiovascular events (22).

Loss of weight and reduction of sodium intake in patients with hypertension are effective in reducing echocardiographic LVH (23). Aggressive blood pressure control should be used to cause regression of LVH (21). A meta-analysis of 109 treatment studies including 2,357 patents with hypertension showed that angiotensinconverting enzyme inhibitors were the most effective antihypertensive drugs in reducing left ventricular mass (24). This analysis showed that angiotensin-converting enzyme inhibitors, beta blockers, and calcium channel blockers reduced left ventricular mass by reducing wall thickness, whereas diuretics reduced left ventricular mass by reducing left ventricular volume (24). Alpha-adrenergic blockers (25) and direct-acting vasodilators (26) did not reduce left ventricular mass.

\section{Acknowledgements}

None.

\section{Footnote}

Conflicts of Interest: The author has no conflicts of interest to declare.

\section{References}

1. Aronow WS, Ahn C, Kronzon I, et al. Congestive heart failure, coronary events and atherothrombotic brain infarction in elderly blacks and whites with systemic hypertension and with and without echocardiographic and electrocardiographic evidence of left ventricular hypertrophy. Am J Cardiol 1991;67:295-99.

2. Aronow WS, Fleg JL, Pepine CJ, et al. ACCF/AHA 2011 expert consensus document on hypertension in the elderly: a report of the American College of Cardiology Foundation Task Force on Clinical Expert Consensus Documents. Circulation 2011;123:2434-506.

3. Levy D, Garrison RJ, Savage DD, et al. Left ventricular mass and incidence of coronary heart disease in an elderly cohort. The Framingham Heart Study. Ann Intern Med 1989;110:101-7.

4. Koren MJ, Devereux RB, Casale PN, et al. Relation of left ventricular mass and geometry to morbidity and mortality in uncomplicated essential hypertension. Ann Intern Med 
1991;114:345-52.

5. Kannel WB, Dannenberg AL, Levy D. Population implications of electrocardiographic left ventricular hypertrophy. Am J Cardiol 1987;60:85I-93I.

6. Aronow WS, Koenigsberg M, Schwartz KS. Usefulness of echocariographic left ventricular hypertrophy in predicting new coronary events and atherothrombotic brain infarction in patients over 62 years of age. Am J Cardiol 1988;61:1130-2.

7. Levy D, Garrison RJ, Savage DD, et al. Prognostic implications of echocardiographically determined left ventricular mass in the Framingham Heart Study. N Engl J Med 1990;322:1561-6.

8. Gardin JM, McClelland R, Kitzman D, et al. M-mode echocardiographic disease predictors of six-to seven -year incidence of coronary heart disease, stroke, congestive heart failure, and mortality in an elderly cohort (the Cardiovascular Health Study). Am J Cardiol 2001;87:1051-7.

9. Aronow WS, Ahn C. Association of electrocardiographic left ventricular hypertrophy with the incidence of new congestive heart failure. J am Geriatr Soc 1998;46:1280-1.

10. Gerdts E, Okin PM, Boman K, et al. Association of heart failure hospitalizations with combined electrocardiography and echocardiography criteria for left ventricular hypertrophy. Am J Hypertens 2012;25:678-83.

11. Desai CS, Bartz TM, Gottdiener JS, et al. Usefulness of left ventricular mass and geometry for determining 10year prediction of cardiovascular disease in adults aged $>65$ years (from the Cardiovascular Health Study). Am J Cardiol 2016;118:684-90.

12. Bluemke DA, Kronmal RA, Lima JA, et al. The relationship of left ventricular mass and geometry to incident cardiovascular events. the MESA (Multi-Ethnic Study of Atherosclerosis) Study. J Am Coll Cardiol 2008;52:2148-55.

13. Drazner MH. The progression of hypertensive heart disease. Circulation 2011;123:327-34.

14. Aronow WS, Schwartz KS, Koenigsberg M. Value of five electrocardiographic criteria correlated with echocardiographic left ventricular hypertrophy in elderly patients. Am J Noninvas Cardiology 1987;1:152-4.

15. Casale PN, Devereux RB, Kligfield P, et al. Electrocardiographic detection of left ventricular hypertrophy. Development and prospective validation of improved criteria. J Am Coll Cardiol 1985;6:572-80.

16. Verdecchia P, Schillaci G, Borgioni C, et al. Adverse prognostic significance of concentric remodeling of the left ventricle in hypertensive patients with normal left ventricular mass. J Am Coll Cardiol 1995;25:871-8.

17. Lavie CJ, Milani RV, Ventura HO, et al. Left ventricular geometry and mortality in patients $>70$ years of age with normal ejection fraction. Am J Cardiol 2006 98:1396-9.

18. Devereux RB, Wachtell K, Gerdis E, et al. Prognostic significance of left ventricular mass change during treatment of hypertension. JAMA 2004;292:2350-6.

19. Okin PM, Devereux RB, Jern S, et al. Regression of electrocardiographic left ventricular hypertrophy during antihypertensive treatment and the prediction of major cardiovascular events. JAMA 2004;292:2343-9.

20. Okin PM, Devereux RB, Harris KE, et al. Regression of electrocardiographic left ventricular hypertrophy is associated with less hospitalization for heart failure in hypertensive patients. Ann Intern Med 2007;147:311-9.

21. Lønnebakken MT, Izzo R, Mancusi C, et al. Left ventricular hypertrophy regression during antihypertensive treatment in an outpatient clinic (the Campania Salute Network. J Am Heart Assoc 2017;6(3). pii:e004152.

22. Pierdomenico SD, Cuccurullo F. Risk reduction after regression of echocardiographic left ventricular hypertrophy in hypertension: a meta-analysis. Am J Hypertens 2010;23:876-81.

23. Liebson PR, Grandits GA, Dianzumba S, et al. Comparison of five antihypertensive monotherapies and placebo for change in left ventricular mass in patients receiving nutritional-hygienic therapy in the Treatment of Mild Hypertension Study (TOMHS). Circulation 1995;91:698-706.

24. Dahlöf B, Pennert K, Hansson L. Reversal of left ventricular hypertrophy in hypertensive patients. A metaanalysis of 109 treatment studies. Am J Hypertens 1992;5:95-110.

25. Drayer JIM, Gardin JM, Weber MA, et al. Cardiac muscle mass during vasodilation therapy of hypertension. Clin Pharmacol Ther 1983;33:727-32.

26. Julien J, Dufloux MA, Prasquier R, et al. Effects of captopril and minoxidil on left ventricular hypertrophy in resistant hypertensive patients: a 6 month double-blind comparison. J Am Coll Cardiol 1990;16:137-42.

Cite this article as: Aronow WS. Hypertension and left ventricular hypertrophy. Ann Transl Med 2017;5(15):310. doi: 10.21037/atm.2017.06.14 